\title{
A arena da saúde na dinâmica do tempo presente
}

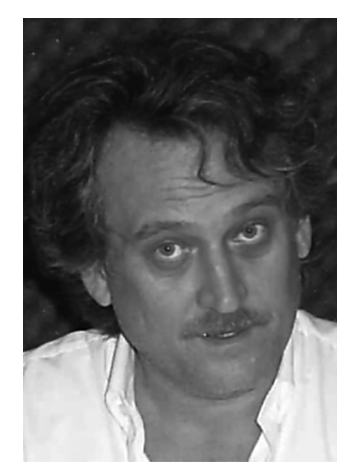

\section{Carlos José Saldanha Machado}

Editor Científico da RECIIS

csaldanha@cict.fiocruz.br
Caros leitores, sejam bem-vindos à RECIIS, um espaço acadêmico virtual de debates, reflexões, conexões e interconexões de idéias entre profissionais oriundos de instituições diversas e singulares. A RECIIS é uma revista eletrônica de acesso livre voltada para o compartilhamento e divulgação da produção científica que aborda as várias dimensões da dinâmica da arena da saúde, dimensões relacionadas às questões da comunicação, da informação e da inovação científica e tecnológica, numa perspectiva multidisciplinar e transnacional. As várias dimensões da saúde a serem comentadas a seguir serão desenvolvidas ao longo de cinco seções que estruturam a RECIIS: Artigos Originais, Artigos de Revisão, Pesquisas em Andamento, Avanços Tecnológicos e Ensaios. As outras três seções são Editorial, Cartas e Resenhas.

Ao longo das últimas décadas, a evolução do conceito de saúde tem sido uma decorrência de avanços científicos e tecnológicos, estudos empíricos, reflexões teóricas, embates políticos e vivências que foram pouco a pouco sendo apropriadas pelo conjunto das sociedades ocidentais, englobando questões referentes ao ambiente, ao grau de desenvolvimento sócio-cultural, à possibilidade de renda e trabalho, à redução da violência, à organização dos transportes urbanos, entre outros, superando o conceito originário de saúde que desencadeou as ações tradicionais da saúde pública ${ }^{1}$ (MEADE and EARINCKSON, 2000; SACHS, 2001; WHO, 2004). Hoje, o nível de saúde das pessoas reflete a maneira como vivem, numa interação dinâmica entre potencialidades individuais e condições de vida. Não se pode compreender ou transformar a situação de uma pessoa ou de uma coletividade sem levar em conta que ela é produzida nas relações com o meio físico, social e cultural. Falar de saúde implica, portanto, levar em conta, por exemplo, a qualidade do ar que se respira e da água que se bebe, o consumismo desenfreado e a miséria, a degradação social e ambiental, a desnutrição e a hipernutrição, as formas de inserção das diferentes parcelas da população no mundo do trabalho, os sistemas de classificação que organizam a realidade, os estilos de vida pessoal, o acesso às inovações de processos, produtos e serviços, os regimes de produção e de regulação dos conhecimentos científicos e tecnológicos, as questões de gênero e ciência e a onipresença da mudança nas sociedades contemporâneas.

Mas, ao mesmo tempo, saúde é uma palavra que designa um espaço de ações, práticas e atividades públicas e privadas desenvolvidas por atores heterogêneos organizados em redes com extensão e topologia variada, uma arena de disputas ideológicas, utópicas, políticas, econômicas e técnico-científicas expressas em inúmeros conceitos inter-relacionados, com maior ou menor grau de aceitação, tais como, "atenção primária em saúde", "promoção da saúde”, "educação em saúde”, "saúde ambiental”, "saneamento ambiental”, "sistemas de saúde”, "avaliação tecnológica em saúde", "sistemas de inovação em saúde"... A complexidade desta arena, que varia 
no espaço geográfico e no tempo histórico, inclui hoje do capitalismo industrial às populações nativas, sejam indígenas, camponesas ou extrativistas, passando por movimentos sociais urbanos e rurais, por comunidades acadêmicas, igrejas, sindicatos, associações, organizações não-governamentais, fundações públicas e privadas, agências de cooperação e agências multilaterais como o Banco Mundial, a Organização Mundial de Saúde, o Banco Interamericano de Desenvolvimento.

$\mathrm{Na}$ arena da saúde, a comunicação e informação desempenham um papel central, uma função estratégica como insumo essencial para a tomada de decisões diversas e o exercício da cidadania. Face à complexidade cada vez maior dos problemas enfrentados pelas ciências, pelas tecnologias, pela gestão dos serviços do Estado e pelo seu controle social, surgem novos modos de produzir conhecimentos, de tratá-los e de divulgá-los, como a Internet, por exemplo, impondo às instituições, sobretudo públicas, a constante atualização de formas de gestão da informação e da comunicação e do uso das tecnologias associadas (BRAMAN, 2007; SILVA e MELO, 2001; THE ROYAL SOCIETY, 2006).

Como decorrência da insofismável dimensão antropológica da comunicação e da informação, isto é, a visão de mundo incorporada nos processos comunicacionais e informacionais, não há lugar na arena da saúde para uma concepção redutora da comunicação e da informação às suas tecnologias. Com nos lembra WOLTON (1997), a comunicação é provavelmente uma das atividades humanas em relação à qual o homem menos se distancia, uma vez que é diretamente constitutiva da sua relação com o mundo. Comunicação nesta arena, mas não exclusivamente nela, envolve grandes fluxos de informação e discursos que concorrem para a construção e a transformação de sentidos sociais a partir dos processos de divulgação científica e do uso de sistemas tecnológicos como a imprensa escrita, o rádio, a televisão e a Internet para informar sobre saúde, ciência, tecnologia e inovação, mas não se reduz a nenhum deles. Uma vez que não há democracia sem comunicação, a comunicação transcende o esquema funcionalista do emissor/receptor, em direção a dimensões da interlocução, da busca do diálogo articulado com outros processos sociais, como o da educação e da popularização da ciência, compartilhados e mediados pelos meios de comunicação, mas não determinados apenas por eles. Informação e comunicação são, portanto, inseparáveis porque, ainda segundo WOLTON (1997), se a primeira tem como objetivo dar forma ao mundo, dar conta dos acontecimentos, dos fatos e contribuir diretamente para o funcionamento de sociedades complexas, a segunda se constitui como o meio de difundir essas informações e de construir as representações.

No cenário mundial, as políticas e estratégias setoriais de comunicação e informação encontram-se no eixo central das possibilidades de geração de novos processos e produtos, e de mudanças nos modelos institucionais de gestão e nas relações internacionais (MODY, 2003; MOWLANA, 1997). Mais do que nunca é nos processos de comunicação e informação que tem início e desdobramento a maioria das ações na saúde pública, nas ciências da vida (BAKER and CHEUNG, 2007) e no desenvolvimento tecnológico para a saúde (HACHE, 2005; THE ROYAL SOCIETY, 2006).

Como os sistemas tecnológicos se tornam mais integrados, mais atualizados e maiores, o desenvolvimento tecnológico se torna mais complexo, dependente da pesquisa em inúmeras áreas, de tal forma que o processo de desenvolvimento não se dá em seqüência, nem obviamente, a partir de um conjunto claro de projetos de pesquisa. $\mathrm{O}$ desenvolvimento de um determinado produto ou tecnologia depende da pesquisa em muitas disciplinas, e a pesquisa em disciplinas como, por exemplo, a bioinformática, a genômica, a proteômica e a vacinologia, além de tantas outras, alimenta inúmeros desenvolvimentos tecnológicos. A progressão da idéia à pesquisa até à aplicação tecnológica não é mais linear apenas, também ocorre muito mais rápida do que há apenas vinte anos atrás. Sob estas novas circunstâncias, a tradicional distinção entre pesquisa pura e pesquisa aplicada fica desprovida de fundamentação empírica quando se olha a tradução para os campos biotecnológicos e biomédicos e os avanços científicos exponenciais nas ciências da vida. Por exemplo, as biotecnologias se constituem num conjunto de técnicas, métodos e procedimentos utilizando sistemas biológicos para desenvolver novos produtos, procedimentos e/ou serviços através de colaborações entre pesquisadores de diferentes disciplinas com a biologia, a física, a matemática e a informática, localizados em instituições e países diversos.

Recentemente, tornou-se lugar comum dizer que as ciências, as tecnologias e as inovações terão uma importância crescente no bem-estar de todas as pessoas, sobretudo porque assumiram o lugar do motor da história e da economia. Ninguém pode negar a incrível penetração que as tecnologias da informação e da comunicação, os novos materiais e as biotecnologias (diagnóstico molecular, terapia gênica, terapia celular, vacinas recombinantes, regeneração de órgãos pelas células-tronco etc.) passaram a ter em nossas vidas. Embora a conversão das ciências e das tecnologias em produtos comerciais que atendem às necessidades das sociedades seja dominada amplamente pelo setor privado, o setor público tem seu papel a desempenhar, sobretudo quando se constata a coexistência entre grandes avanços tecnológicos e ampliação e diversificação das desigualdades sociais entre nações e, no interior de cada uma, entre regiões, classes e grupos sociais (GOBAL FORUM FOR HEALTH RESEARCH, 2002; MEADE et al., 2000; SACHS, 2001; UN MILLENNIUM PROJECT, 2005; WHO, 2004).

É com alegria, satisfação, esperança e otimismo que termino a apresentação deste número inaugural da RECIIS, dando ênfase em três idéias-chave que poderiam ser aqui enunciadas da epistemologia subjacente a esse novo espaço editorial, financiado inteiramente pelo Instituto de Comunicação e Informação Científica e Tecnológica em Saúde da Fundação Oswaldo Cruz²: primeiro, a multiplicidade do real, inesgotável, impede a unidade de um saber totalizante; segundo, a complexidade do objeto saúde a ser conhecido é irredutível a uma decomposição em elementos simples e, finalmente, o objeto saúde a ser 
conhecido é uma realidade dinâmica irredutível a uma estrutura estática.

Muito obrigado a todos(as) aqueles(as) que se escondem por detrás desse nome de Editor por tornarem possível o nascimento da RECIIS em apenas cinco meses de trabalho. Aguardamos agora as respostas dos nossos leitores e esperamos que se sintam encorajados a submeterem seus trabalhos aos futuros números da RECIIS.

\section{Notas}

1. No Brasil, essa "nova complexidade" é anunciada na Constituição da República de 1988, em seus artigos 196 e 198 Artigo 196 - A saúde é direito de todos e dever do Estado, garantido mediante políticas sociais e econômicas que visem à redução do risco de doença e de outros agravos e ao acesso universal igualitário às ações e serviços para sua promoção, proteção e recuperação; Artigo 198 - As ações e serviços públicos de saúde integram uma rede regionalizada e hierarquizada e constituem um sistema único, organizado de acordo com as seguintes diretrizes: I - descentralização, com direção única em cada esfera de governo; II - atendimento integral, com prioridade para as atividades preventivas, sem prejuízo dos serviços assistenciais; III - participação da comunidade.

2. Vinculada ao Ministério da Saúde, a Fundação Oswaldo Cruz (Fiocruz) tem como missão gerar, absorver e difundir conhecimentos científicos e tecnológicos em saúde, por meio do desenvolvimento integrado de pesquisa, ensino, informação, serviços e produção de bens. Seu objetivo é proporcionar apoio estratégico ao Sistema Único de Saúde (SUS) e contribuir para a melhoria da qualidade de vida da população e para o exercício pleno da cidadania. Criada pelo poder público em 1900, a Fiocruz fundamenta-se na primazia da atividade experimental. A instituição une ciência, tecnologia, formação de recursos humanos, prestação de serviços, produção e gestão para solucionar os problemas nacionais de saúde pública (FUNDAÇÃO OSWALDO CRUZ, 2007).

\section{Referências bibliográficas}

BRAMAN, S. Change of State: Information, Policy, and Power. Cambridge, MA: The MIT Press, 2007.

FUNDAÇÃO OSWALDO CRUZ. Relatório de Atividades. Rio de Janeiro: FIOCRUZ. 2007.

GLOBAL FORUM FOR HEALTH RESEARCH. 10/90

Report on Health Research 2001-2002. Geneva: Global Forum on Health Research, 2002.

MEADE, M. S.; EARICKSON, R. J. Medical geography. $2^{\text {nd }}$ ed. New York: The Guilford Press, 2000.

MODY, B. (Ed.). International and Development Communication: A 21 st-Century Perspective. London: Sage, 2003.

MOWLANA, H. Global Information and World Communication: New Frontiers in International Relations. London: Sage, 1997.

SACHS, J. D. Macroeconomics and Health: Investing in Health for Economic Development. Geneva: World Health Organization, 2001.

UN Millennium Project. Innovation: Applying Knowledge in Development. Task force on Science, Tecnology and Innovation, 2005.

WHO. World Report on Knowledge for a Better Health: Strengthening Health Systems. Geneva: World Health Organization, 2004.

WOLTON, D. Penser la communication. Paris: Flammarions, 1997.

\section{Sobre o editor}

\section{Carlos José Saldanha Machado}

Doutor em Antropologia Social pela Université Paris V - Sciences Humaines Sorbonne, mestre em Ciências da Engenharia de Produção (área de Política de Ciência e Tecnologia) pela Coordenação dos Programas de Pós-Graduação em Engenharia da Universidade Federal do Rio de Janeiro. Atualmente, (1) na Fundação Oswaldo Cruz, é Pesquisador em Ciência e Tecnologia e Chefe do Laboratório de Ciência, Tecnologia e Inovação em Saúde do Instituto de Comunicação e Informação Científica e Tecnológica em Saúde; (2) na Universidade do Estado do Rio de Janeiro, é professor do Programa de Pós-Graduação em Meio Ambiente (Doutorado) responsável pela disciplina "Política Ambiental Brasileira"; (3) no Ministério da Educação, é Avaliador Institucional e de Cursos do Sistema Nacional de Avaliação da Educação Superior. Atua na área de sociologia e antropologia, com ênfase: nos estudos sociais da ciência, da tecnologia e da inovação em saúde; na gestão da pesquisa em saúde; nas políticas públicas de meio ambiente e saúde. Publicou, ao longo dos últimos 5 anos 4 livros e inúmeros artigos no Brasil. Seus novos projetos incluem pesquisas sobre: o novo regime de produção e de regulação do conhecimento científico e tecnológico em biomedicina; as mudanças recentes na configuração da biociência, especialmente nas infra-estruturas de produção do conhecimento; a transposição local de modelos internacionais de organização da pesquisa em biomedicina; a política de ciência, tecnologia e inovação em saúde da Fundação Oswaldo Cruz. 